\title{
Why Do Options Prices Predict Stock Returns? \\ Evidence from Analyst Tipping*
}

\author{
Tse-Chun $\operatorname{Lin}^{\mathrm{a} \dagger}$ Xiaolong $\mathrm{Lu}^{\mathrm{a} \ddagger}$ \\ ${ }^{a}$ Faculty of Business and Economics, University of Hong Kong, Hong Kong
}

September 2014

\begin{abstract}
We study the role of analysts and options traders in the information transmission between options and stock markets. We first show that the predictive power of option implied volatilities (IVs) on stock returns more than doubles around analyst-related events, indicating that a significant proportion of the options predictability on stock returns comes from informed options traders' information about upcoming analyst-related news. We examine three explanations for this finding: tipping, reverse tipping and common information. We find that analyst tipping to options traders is the most consistent explanation of these predictive patterns.

JEL Classification: G12, G14, G17

Keywords: Informed traders, analyst tipping, implied volatility spread, implied volatility skew, market liquidity

*The authors are grateful to Gurdip Bakshi, Geert Bekaert, Dion Bongaerts, Lauren H. Cohen, Joost Driessen, T. Clifton Green, Mark Grinblatt, Campbell Harvey, Antti Ilmanen, Kewei Hou, Alexander Ljungqvist, Bradley Paye, Neil Pearson, Markus Schmid, Sheridan Titman, Avanidhar Subrahmanyam, Marti G. Subrahmanyam, Jun Tu, and Gerben de Zwart for valuable suggestions. We also thank conference participants at the 2012 Asian Finance Association annual meeting, the 2012 China International Conference in Finance, the 2012 Financial Management Association annual meeting, the 2012 Inquire Europe Annual Symposium, the 2012 OptionMetrics Users Conference, the 2013 Annual Conference on Advances in the Analysis of Hedge Fund Strategies, the 2013 European Finance Association annual meeting, and the 2013 Western Finance Association annual meeting; seminar participants at All Pensions Group-Netherlands, National Chengchi University, National Taiwan University, and the University of Hong Kong for very helpful comments; and the Faculty of Business and Economics at the University of Hong Kong and the Research Grants Council of the Hong Kong SAR government for research support. Any remaining errors are our sole responsibility.
\end{abstract}

†Tel.: +852-2857-8503; fax: +852-2548-1152; e-mail address: tsechunlin@hku.hk

†Tel.: +852-6685-0628; fax: +852-2548-1152; e-mail address: xllu@connect.hku.hk 


\title{
Why Do Options Prices Predict Stock Returns?
}

\author{
Evidence from Analyst Tipping
}

September 2014

\begin{abstract}
We study the role of analysts and options traders in the information transmission between options and stock markets. We first show that the predictive power of option implied volatilities (IVs) on stock returns more than doubles around analyst-related events, indicating that a significant proportion of the options predictability on stock returns comes from informed options traders' information about upcoming analyst-related news. We examine three explanations for this finding: tipping, reverse tipping and common information. We find that analyst tipping to options traders is the most consistent explanation of these predictive patterns.
\end{abstract}

JEL Classification: G12, G14, G17

Keywords: Informed traders, analyst tipping, implied volatility spread, implied volatility skew, market liquidity 


\section{Introduction}

It is often argued that informed traders may take advantage of the high leverage in the options market to capitalize on their private information (Black (1975)). In addition, options can be used to trade on negative information in the presence of short-sale constraints on the underlying stocks. One seminal study by Easley, O’Hara, and Srinivas (1998) proposes that options are preferred by informed traders when the implicit leverage is high and the options market is liquid. A recent stream of empirical papers documents the informational leading role of the options market relative to the stock market. ${ }^{1}$ For example, Pan and Poteshman (2006) show that the put to call trading volume ratio can negatively predict future stock returns. Cremers and Weinbaum (2010) show that the deviation from put-call parity reflects information about future stock price changes, and Xing, Zhang, and Zhao (2010) find that the firm-level options volatility skew can predict future cross-sectional equity returns.

A separate stream of literature studies stock market trading patterns in the days before analyst news. Among others, Irvine, Lipson and Puckett (2007) report the abnormal trading volume of institutional investors before the upcoming initial buy recommendations of analysts, while Christophe, Ferri and Hsieh (2010) find abnormal short-selling activity before analyst downgrades. Both articles argue that analysts might tip certain groups of investors about the upcoming analyst news. ${ }^{2}$

In this paper, we combine these two strands of the literature. If analysts indeed tip investors about upcoming analyst news, for the reasons discussed above, options markets

\footnotetext{
${ }^{1}$ See, for example, Chakravarty, Gulen, and Mayhew (2004); Ni, Pan, and Poteshman (2008); Roll, Schwartz, and Subrahmanyam (2010); and Johnson and So (2012).

${ }^{2}$ On the other hand, Blau and Wade (2012) argue that the abnormal short sales before analyst recommendations are speculative trades rather than informed trades based on tips from analysts.
} 
might be the ideal place to exploit such information. We therefore study the patterns in options prices prior to analyst news events. First, we establish that options prices predict the stock market's response to analyst news. ${ }^{3}$ Second, and most importantly, we distinguish between three potential explanations for this finding: tipping (from analysts to options traders), reverse tipping (from options traders to analysts), or common information (of analysts and options traders). As discussed below in detail, our results are most consistent with the tipping hypothesis.

Our findings are related to those in two independent studies by Hayunga and Lung (2013) and Lung and Xu (2014). Hayunga and Lung (2013) show that options trading reflects information about analysts' recommendation consensus changes. Lung and Xu (2014) show abnormal option trading activities before analyst initiations, and the authors relate this pattern to analyst tipping. We differ from these two papers in several key aspects: First, we conduct a more comprehensive analysis of the channel through which the lead-lag correlation between informed options trading measures and analyst-related news can be manifested. We exclude a third possible channel, i.e., the common-information channel, which is neglected by Hayunga and Lung (2013). Second, we have a more complete sample of analyst-related events as a result of including the analyst forecast revision in the analysis. Third, we decompose the predictability of options trading on stock returns regarding days with specified analyst-related events and other days. Last but not least, we have a better execution of the estimated standard errors in the pooled OLS regressions. We double-cluster the estimated standard errors along

\footnotetext{
${ }^{3}$ Analyst-related events have been shown to contain new information that moves the stock price. See, for example, Womack (1996); Barber, Lehavy, McNichols, and Trueman (2001); and Jegadeesh, Kim, Krische, and Lee (2004).
} 
both firm and time dimensions.

Our paper also makes contributions to the literature by settling the debate on whether the options market leads the stock market in the price-discovery process. Many papers have linked the informed options trading and lead-lag relation between the option and stock markets to corporate events, such as earnings announcements (Xing, Zhang, and Zhao (2010); Roll, Schwartz, and Subrahmanyam (2010); Jin, Livnat, and Zhang (2012); and Johnson and So (2012)), mergers and acquisitions (Cao, Chen, and Griffin (2005); and Chan, Ge, and Lin (2013)), and bankruptcy (Ge, Humphery-Jenner, and Lin (2013)). However, there are other studies arguing that options do not contribute to the equity price discovery process. Chan, Chung, and Fong (2002) show that stock net trading volume can predict future options quotes revisions, but not vice versa. Their results suggest that informed investors only initiate their trades in the stock market. Muravyev, Pearson, and Broussard (2013) find that options quotes do not contain any non-public information about future underlying stock prices, and it is the stock price that leads the options quotes in the price discovery process.

Empirical, our analysis focuses on three analyst news events: the analyst recommendation change, the analyst forecast revision, and the analyst initiation of coverage. We employ two proxies for the options trading activities of informed traders based on previous studies, the implied volatility (IV) spread (Cremers and Weinbaum (2010)) and the IV skew (Xing, Zhang, and Zhao (2010)). The IV spread, which is the difference in IVs between matched pairs of call and put options with identical strike prices and maturities, has been demonstrated to be a positive predictor of equity returns. ${ }^{4}$ On the other hand, the IV skew, defined as the

\footnotetext{
${ }^{4}$ See, for example, Ofek, Richardson, and Whitelaw (2004); Bali and Hovakimian (2009); and Cremers and
} 
difference between the IVs of out-of-the-money (OTM) put options and at-the-money (ATM) call options, is shown to be negatively associated with future stock returns. ${ }^{5}$ Intuitively, if informed traders anticipate a drop in the stock price, they are more likely to buy put options to capitalize on their private information, especially OTM puts. In a market that is not perfectly liquid, this will lead to a price increase in those put options, resulting in a decrease of the IV spread and an increase of the IV skew, and vice versa.

Using options pricing data and analyst-related news data from January 1996 to December 2010, we first perform regressions of stock returns on each informed options trading proxy. Consistent with the results of previous studies, we document that the IV spread (IV skew) carries significantly positive (negative) information for future excess returns. Firms with lower IV spreads or higher IV skews experience lower stock returns in the following week. We then add interaction terms with dummy variables indicating days with the three analyst-related events and calculate the proportion of the predictability of options trading on excess returns that is associated with the events. We find that $10.74 \%$ (13.20\%) of the predictability of the IV spread (IV skew) comes from the days with analyst recommendation changes, analyst forecast revisions, and analyst initiation of coverage. Because the event days constitute only $4.47 \%$ (5.26\%) of the IV spread (IV skew) sample, the predictive power of the IV spread and skew more than doubles on analyst-related news days compared with no analyst-related news days. Nevertheless, a large part of the predictability is obtained on other days, which shows that options traders have information that goes beyond the analyst-related events that we study.

Weinbaum (2010).

${ }^{5}$ See, for example, Bates (1991); Bollen and Whaley (2004); and Xing, Zhang, and Zhao (2010). 
We then turn to the main contribution of the paper, that is, our study of the interplay between analysts and option traders in more detail. We discuss three hypotheses that might explain this correlation. First, analysts could inform options traders about their upcoming recommendation change, earnings forecast revision, or initiation coverage (“analyst tipping”). Second, options traders could leak their trading information to analysts, leading to recommendation changes or forecast revisions by analysts ("reverse tipping”). Third, analysts and options traders may independently gather similar information, but options traders can exploit this more quickly (“common information”).

We focus on the analyst initiation events to distinguish between these explanations. Irvine, Lipson, and Puckett (2007) argue that analyst initiation is least likely to be related to "reverse tipping” because the initiation occurs at very low frequency and it is too costly to respond to tips that are contained in institutional trading. The average analyst in our sample only initiates coverage for 0.77 firms each year. This number should be much larger if sell-side analysts respond to informed traders' trading activities to issue initial recommendations. Our results show that both the IV spread and IV skew are significant predictors of analysts' initial recommendations, which points towards the tipping hypothesis.

To distinguish the common-information hypothesis from the tipping hypothesis, we follow Christophe, Ferri, and Hsieh (2010) to examine the relationship between the pre-event IV spread/skew and the standardized unexpected earnings (SUEs) in the quarter that precedes the analyst initiation. The earnings report is undoubtedly one of the most important information sources with which to evaluate a firm's performance. We sort firms into terciles based on the pre-event IV spread/skew. If sell-side analysts and options traders both analyze 
firms’ most recent quarterly earnings, we expect to see higher (lower) SUEs for firms with higher IV spread (IV skew). On the contrary, we find no significant patterns for the SUEs, which is inconsistent with the common-information argument. In sum, compared with the other two hypotheses, our results are most supportive of the analyst-tipping hypothesis.

We conduct a series of additional tests to validate our results, where we focus on the analyst initiations, as these events are most important for the tipping hypothesis. First, we investigate whether the options market liquidity is an important factor driving informed traders to the options market. We find that the proportion of options trading predictability on stock returns that is associated with the analyst initiation decreases with the bid-ask spreads of options, which is in line with the argument by Easley, O’Hara, and Srinivas (1998) that the options market is more attractive to informed traders compared with the stock market when options liquidity is high. Moreover, we examine the IV spread and skew in the post-event weeks and find that the IV spread and skew revert to their normal levels, suggesting that informed traders believe that the market has fully reacted to the event news and therefore close their options positions. ${ }^{6}$ Finally, we cross-sectionally sort firms into decile portfolios based on IV spread/skew. We find that the four-factor abnormal returns during the week after portfolio formation are larger in magnitude on the days in which analysts initiate their first recommendations than in the no-event days. This is consistent with our major finding that more informed investors participate in the options market around analyst initiations.

For robustness purposes, we perform a sub-period analysis using data from 2002 to 2010 to address the concern of inaccurate analyst report time stamps in I/B/E/S from 1994 to 2001

\footnotetext{
${ }^{6}$ It is also in line with the notion that informed traders are more likely to be contrarian traders, as argued, for example, by Brennan and Cao (1996), Lakonishok and Lee (2001), and Watanabe (2008).
} 
and find qualitatively similar results. Last but not least, we assess the influence of the short-selling activities of the informed investors. ${ }^{7}$ Investors who are informed about the analyst-related news could also trade in the short-selling market, and the options prices would be influenced by the changes in the equity-lending fees through the put-call parity relationship. To address this concern, we control for the equity-lending fee in the analyses, and our results are not changed.The remainder of the paper is organized as follows. Section 2 describes the data and provides summary statistics for the analyst-related events and informed options trading measures. Section 3 presents the empirical results for the main hypothesis. Section 4 discusses three hypotheses of how investors become informed of analyst-related news. Section 5 presents three additional tests. Section 6 shows the robustness checks. Section 7 concludes the paper.

\section{Data and summary statistics}

In this section, we describe the data used in the study and discuss the summary statistics for the analyst-related events and the informed options trading measures.

\subsection{Data description}

Our sample period covers from January 1996 to December 2010. We use American-style options data from OptionMetrics, which is a comprehensive database providing end-of-day bid and ask quotes, open interests, trading volumes and other relevant information for all options on US exchange listed equities. ${ }^{8}$ The database calculates the option implied volatility

\footnotetext{
7 The empirical results for the robustness tests are non-tabulated for the sake of brevity. They are available upon request.

${ }^{8}$ More details can be found in the "Ivy DB's OptionMetrics Manual,” which is available at: http://wrds-web.wharton.upenn.edu/wrds/support/Data/_001Manuals\%20and\%200verviews/_105OptionMetrics/IvyDB' s\%200ptionMetrics\%20Manual.pdf.cfm.
} 
using a proprietary pricing algorithm that is based on the industry-standard Cox-Ross-Rubinstein (CRR) binomial tree model (Cox, Ross, and Rubinstein (1979)), which accommodates underlying securities with either discrete dividend payments or a continuous dividend yield and is widely used for pricing American options.

For the options data, we employ the following filters following Xing, Zhang, and Zhao (2010) to reduce the effects of illiquid options and outliers: i) the volume of the underlying stock is positive; ii) the price of the underlying stock is above \$5; iii) the implied volatility of the option is between 0.03 and 2; iv) the mean of the best bid and best ask prices of the options is above $\$ 0.125$; v) the open interest of the options is positive; vi) the trading volume of the options is not missing; and vii) the time to maturity of the options is within 10 to 60 days. After applying all of the above criteria, we have daily options data for 6,767 distinct US listed stocks throughout the whole sample period.

The events data of the analyst recommendation changes, the analyst forecast revisions, and the analyst initiations are extracted from the Institutional Brokers Estimate System (I/B/E/S). The stock trading data are from the Center for Research in Security Prices (CRSP). The general accounting data are provided by the Compustat.

\subsection{Analyst-related events}

The analyst-related events are defined as follows: the analyst recommendation change is the total number of notches changed for a stock during a trading day from all individual analysts (where an analyst recommendation equals a number from 5 to 1, indicating strong buy, buy, hold, underperform, and sell, respectively); the analyst forecast revision is the change of the 
consensus analyst forecast defined as the mean of the earnings estimates from individual analysts; the analyst initiation is the very first recommendation that an analyst gives on a stock. If multiple initiations occur for one stock within one trading day, we take the average of all of the initial recommendations. ${ }^{9}$ To adjust for the possible clustering of analyst reports around earnings dates, we exclude the analyst-related events that are within the five-day window of the quarterly earnings announcement dates.

[Table 1 to be inserted here]

Panel A of Table 1 provides summary statistics on the three analyst-related events. In our sample, the analyst forecast revision occurs most frequently. For the analyst recommendation change and analyst forecast revision, the average events are in negative values, and both are quite volatile across the sample. The mean analyst recommendation change is -0.13 , while its standard deviation is 1.53 . The analyst forecast revision has a mean of -0.005 , and its standard deviation is 0.10 . By contrast, the mean value of analysts' initial recommendations is 3.82, indicating that the average initial recommendation is better than "hold" and leans towards "buy."

\subsection{Measures of informed options trading}

Based upon the existing literature, we employ two informed options trading measures in this paper: the IV spread and the IV skew.

The IV spread is calculated as described by Cremers and Weinbaum (2010). For stock $i$

\footnotetext{
${ }^{9}$ We obtain the analyst initiation sample following Irvine, Lipson, and Puckett (2007). We find the first recommendation from an analyst on a stock in the I/B/E/S since December 14, 1992. To address the concern that an initiation record could be just a new entry of a brokerage firm into the database, observations are excluded from the sample if the brokerage firm appears in the I/B/E/S for less than six months before the initiation.
} 
on day $t$, which has $n$ pairs of matched call and put options with identical strike prices and expiration dates, the IV spread is calculated to be the open-interest weighted average of the differences in IVs between the matched call and put options: ${ }^{10}$

$$
\operatorname{spread}_{i, t}=\sum_{j=1}^{n_{i, t}} w_{j, t}^{i}\left(I V_{j, t}^{i, c a l l}-I V_{j, t}^{i, p u t}\right)
$$

The IV spread measures the deviations from put-call parity. For American-style options, which allow early exercise, the deviation from put-call parity does not necessarily indicate an arbitrage opportunity. In addition, in the case of transaction costs, there is a range of call and put prices that precludes arbitrage even for European options. Then, in a market in which options are not perfectly liquid, buy or sell pressure may lead to deviations from put-call parity that do not reflect an arbitrage opportunity but rather (informed) trading. In the case of positive information, call-buying pressure may push call IVs up, above put IVs. In the case of negative information, the opposite may occur. If informed traders prefer the options market, the IV spread may then predict future stock returns.

The IV skew is defined as the difference between the IVs of the OTM put options and the ATM call options on the same stock (Xing, Zhang, and Zhao (2010)):

$$
\text { skew }_{i, t}=I V_{i, t}^{\text {OTMP }}-I V_{i, t}^{\text {ATMC }},
$$

A put option is OTM if its moneyness of the strike price to stock price ratio lies between 0.80 and 0.95 . A call option is ATM if its moneyness is between 0.95 and 1.05. In the case of more than one record of OTM put or ATM call options for one stock on one day, we choose

\footnotetext{
${ }^{10}$ We find qualitatively similar results using the options trading volume as the weighting.
} 
the put options with the moneyness closest to 0.95 and the call options with the moneyness closest to 1 . The IV skew thus measures the left shape of the IV function and is found to contain negative predictive information for future stock returns. The intuition is again that informed traders buy OTM put options to express their negative information. ${ }^{11}$ Note that OTM options provide higher leverage than ATM or in-the-money (ITM) options.

Panel B of Table 1 reports descriptive statistics for the IV spread and IV skew. For the full sample period of January 1996 to December 2010, we have a total of 7,083,631 IV spreads calculated for 6,629 distinct firms and 3,613,595 IV skews for 6,082 firms. Consistent with previous studies, the IV spread is negative on average, while the IV skew is positive on average. The average daily cross-sectional mean of the IV spread is $-1.1 \%$, indicating that put options are generally more expensive than the matched call options with the same strike prices and maturities. For the IV skew, the average daily cross-sectional mean is 5.5\%, suggesting that OTM put options are more expensive on average than ATM call options on the same stocks. Both the IV spread and the IV skew exhibit substantial variations. The average daily cross-sectional standard deviation of the IV spread is $6.4 \%$, and it is $6.6 \%$ for the IV skew. ${ }^{12}$

\section{Decomposition of options trading predictability on stock returns}

In this section, we follow the empirical setup used by Boehmer, Jones, and Zhang (2012) to

\footnotetext{
${ }^{11}$ Note that the IV skew may also reflect a risk premium for jump risk. This would imply a positive relation between the IV skew and subsequent stock returns. The existing research does not find an important role of such an effect.

${ }^{12}$ We received a comment from an anonymous referee that the lack of contemporary observations of put and call transactions could possibly add errors to the measures of IV spread and IV skew. It is difficult to address this issue directly due to data limitations. The OptionMetrics only provides daily aggregated options trading data. Nevertheless, this potential measurement error, which adds noise to the estimation, is likely to bias against us to find any significant results. Given that our empirical findings are strong and robust, the concern about the measurement errors is alleviated.
} 
examine whether options traders hold private information on the analyst-related events such that their trading activities in the options market can predict future stock returns. Our main hypothesis in this section is to test whether options trading has predictive power on future excess returns and to what extent the predictability comes from the analyst-related events. The detailed empirical setup is outlined in the following subsection. All estimated standard errors are clustered by firm and calendar quarter to adjust for the cross-sectional and serial correlations in the pooled regression residuals (Petersen (2009)). ${ }^{13}$ We provide a brief discussion of the two-way clustering methodology in the Appendix.

\subsection{Empirical setup for the hypothesis testing}

The empirical estimations are conducted in three steps. In the first step, we study the stock return predictability of IV spread and IV skew. We regress the excess returns on each options trading measure and the control variables:

$$
\begin{aligned}
\text { exret }_{i, t, t+4}= & \beta_{0}+\beta_{1} \text { option }_{i, t-5, t-1}+\beta_{2} \ln \text { size }_{i, t-5, t-1}+\beta_{3} \text { bm }_{i, y-1}+\beta_{4} \text { ret }_{i, w-1}+\beta_{5} \text { ret }_{i, w-24, w-2} \\
& +\beta_{6} \sigma_{i, m-1}+\beta_{7} \text { turnover }_{i, t-5, t-1}+\beta_{8} \text { hskew }_{i, m-1}+\beta_{9} \text { stockbasp }_{i, t-5, t-1} \\
& +\gamma \text { Year fixed effects }+\varepsilon_{i, t},
\end{aligned}
$$

where exret $_{i, t, t+4}$ is the daily excess stock return, calculated as the stock return in excess of the market return averaged over day $t$ to day $t+4$. The variable option $_{i, t-5, t-1}$ refers to the informed trading measures constructed from the options market five trading days before the event. It can take the value of spread $_{i, t-5, t-1}$ or skew $_{i, t-5, t-1}$ (the average IV spread and average IV skew over the pre-event week). ${ }^{14}$

\footnotetext{
${ }^{13}$ If we do not include year fixed effects, it is computationally feasible to cluster the standard error by firm and week. We find very similar results when clustering the estimated standard errors by firm and week.

${ }^{14}$ We choose the prediction window of five trading days following Cremers and Weinbaum (2010); Xing, Zhang, and Zhao (2010); and Boehmer, Jones, and Zhang (2012). We find qualitatively similar results using a three-day
} 
Other explanatory variables controlling for different firm characteristics include the average natural logarithm of the firm's market capitalization during the previous week $\ln \operatorname{size}_{i, t-5, t-1}$, the book-to-market ratio by the end of last calendar year $b m_{i, y-1}$, the cumulative stock return over the previous week ret $_{i, w-1}$, the cumulative stock return over the past 2 to 24 weeks ret $_{i, \mathrm{w}-24, \mathrm{w}-2}$, the stock return volatility in the previous month calculated using daily stock returns $\sigma_{i, m-1}$, the average turnover rate for the previous week calculated as the stock trading volume over the number of shares outstanding turnover $_{i, t-5, t-1}$, the historical skewness of the daily stock returns over the past month $h s k e w_{i, m-1}$, and the average stock bid-ask spread over the previous week defined as the closing ask less the closing bid and divided by the midpoint stockbasp $_{i, t-5, t-1}$. The year fixed effects are also included in the regressions.

If the options market leads the stock market, we expect the IV spread to be positively correlated with future excess returns, which implies a positive estimated value of $\beta_{1}$. Additionally, we anticipate the IV skew to be negatively correlated with future excess returns, which indicates a negative $\beta_{1}$.

In the second step, we add an interaction term between the options trading measure and a dummy variable indicating the occurrence of any of the three events to the regression (3):

$$
\begin{aligned}
\text { exret }_{i, t, t+4}= & \beta_{0}+\left(\beta_{1}+\beta_{2} \text { eventday }_{i, t}\right) * \text { option }_{i, t-5, t-1}+\beta_{3} \text { eventday }_{i, t}+\text { Scontrols }_{i, t-1} \\
& +\gamma \text { Year fixed effects }+\varepsilon_{i, t},
\end{aligned}
$$

where eventday $_{i, t}$ takes the value of 1 if one of the three events takes place for firm $i$ on day $t$, and 0 otherwise. The Controls $_{i, t-1}$ are the lagged control variables described in the previous subsection. 
Therefore, when none of the events takes place, the predictability of options trading on future excess returns is measured as $\beta_{1}$. When any of the events occurs, the predictability becomes $\left(\beta_{1}+\beta_{2}\right)$. Therefore, we decompose the predictability of options trading on stock returns into two parts: the days with specified analyst-related events and other days. The interacted coefficient $\beta_{2}$ indicates the predictability from the event day such that we can calculate the proportion of the predictability that is attributed to informed options traders' private information about the upcoming three types of events. Note that $\left(\beta_{1}+\beta_{2}\right)$ captures the return effect one would obtain from the standard event study.

In the last step, we replace the eventday $_{i, t}$ in the previous step by three individual event dummy variables to test the hypothesis for each analyst-related event separately:

$$
\begin{aligned}
\text { exret }_{i, t, t+4}= & \beta_{0}+\left(\beta_{1}+\beta_{2} \text { revision }_{i, t}+\beta_{3} \text { recommend }_{i, t}+\beta_{4} \text { initiation }_{i, t}\right) * \text { option }_{i, t-5, t-1} \\
& +\beta_{5} \text { revision }_{i, t}+\beta_{6} \text { recommend }_{i, t}+\beta_{7} \text { initiation }_{i, t}+\text { scontrols }_{i, t-1} \\
& +\gamma \text { Year fixed effects }+\varepsilon_{i, t}
\end{aligned}
$$

where recommend ${ }_{i, t}$ equals 1 if an analyst recommendation change takes place, and 0 otherwise; revision $_{i, t}$ equals 1 if an analyst forecast revision takes place, and 0 otherwise; and initiation $_{i, t}$ equals 1 if an analyst initiation takes place for firm $i$ on day $t$, and 0 otherwise.

By the same argument as in regression (4), the interacted coefficients of $\beta_{2}, \beta_{3}$, and $\beta_{4}$ help us gauge the portion of the predictability that comes from informed options traders' private information for each analyst-related event. In particular, studying initiations is important in order to distinguish the various explanations for the predictive results, as discussed below in Section 5 . 


\subsection{Empirical results for the decomposition of options trading predictability}

Table 2 present the regression results on the main hypothesis for the IV spread.

[Table 2 to be inserted here]

The first two columns of Table 2 are for regressions in the first step. The IV spread is positively related to future excess returns, with a t-statistic of 10.43 without controls and 10.04 with control variables. The coefficient estimates indicate that a one standard deviation increase in the IV spread would raise the average daily excess return in the following week by 2.84 basis points.

The third and fourth columns of Table 2 report the regression results for the second step. When we only include the IV spread, its interaction term and the event dummy variable, the IV spread itself carries a significant coefficient of 0.47 (t-statistic $=10.33$ ), and the interaction term has a significant coefficient of 0.62 (t-statistic $=3.50)$. In the fourth column, with the inclusion of all the control variables, the coefficient estimate on the IV spread becomes 0.42 (t-statistic $=9.56)$, and the coefficient estimate on the interaction term is 0.66 (t-statistic $=3.63)$. Hence, the predictability of the IV spread over excess returns on event days is more than double that on non-event days (1.08 vs. 0.42 ).

To further compute the exact percentages of the predictability that come from analyst-related events, we can follow the analysis by Boehmer, Jones, and Zhang (2012): because event days constitute $4.47 \%$ of the whole IV spread sample, the overall predictive power of the IV spread can be measured as: $0.42 *(1-4.47 \%)+(0.66+0.42) * 4.47 \%=0.45$. Therefore, the fraction of the predictability that comes from the informed options traders' 
private information about the three events can be calculated as: $(0.66+0.42) * 4.47 \% / 0.45=$ $10.74 \%$.

The last two columns of Table 2 report the results for the last step. After including the three interaction terms between the IV spread and each analyst-related news dummy and controlling for different firm characteristics and year-fixed effects, the IV spread can still positively predict the excess returns with a t-statistic of 9.54. The predictability becomes significantly stronger on trading days when analyst-related news takes place. The interaction terms with the analyst recommendation dummy, the analyst forecast revision dummy, and the analyst initiation dummy carry significant and positive coefficient estimates. As for the event dummy, the analyst recommendation change dummy and analyst forecast revision dummy carry significantly negative coefficients, while the analyst initiation dummy has a significantly positive coefficient. This is because both the analyst recommendation change and the analyst forecast revision on average contain negative information, as shown in Table 1, which leads to negative impacts on excess stock returns. By contrast, analysts' initial recommendations are more likely to be good news for firms.

Following similar calculations as those in the previous paragraph, because days with analyst recommendation changes, analyst forecast revisions, and analyst initiations make up $1.24 \%, 2.77 \%$, and $0.85 \%$ of the whole IV spread sample, approximately $4.51 \%, 6.05 \%$, and $1.76 \%$ of the predictability of the IV spread on excess returns can be attributed to informed options traders’ private information about the regarded analyst-related event.

[Table 3 to be inserted here] 
We then turn to the IV skew and perform a similar analysis. Table 3 presents the results. The first two columns report the regressions in step one. The relation between the IV skew and future stock returns is significantly negative. When only including the IV skew, the coefficient estimate on it is -0.24 , with a t-statistic of -4.44 . With firm characteristics controlled, the coefficient estimate on the IV skew is -0.24 , with a t-statistic of -5.15 . A one standard deviation increase in the IV skew would decrease the average daily excess return in the following week by 1.60 basis points.

The third and fourth columns of Table 3 provide the results for step two. Without controlling for firm characteristics, the coefficient estimate on the IV skew is -0.23 (t-statistic $=-4.19)$, and the interacted coefficient is $-0.43(\mathrm{t}$-statistic $=-3.20)$. After including all control variables, the IV skew has a statistically significant coefficient of -0.23 , while the interaction term carries a significant coefficient of -0.40 . The results imply that the predictability of the IV skew for stock returns on event days is nearly three times as large as that on non-event days (-0.63 vs. -0.23$)$. If we take into account that the event days make up $5.26 \%$ of the whole IV skew sample, the overall predictive power can be calculated as $-0.23^{*}(1-5.26 \%)$ $+(-0.23+(-0.40)) * 5.26 \%=-0.25$. The fraction of the predictability that is associated with informed options traders' private information about the events can be measured as $(-0.23+$ $(-0.40)) * 5.26 \% /(-0.25)=13.20 \%$.

The last two columns of Table 3 present the results, distinguishing between different types of analyst-related events. The interaction coefficient is significantly negative for analyst recommendation change and analyst forecast revision. As presented in the last column, the IV skew has a significant coefficient of -0.23 (t-statistic $=-4.77)$, and the interaction terms with 
the analyst recommendation change dummy and analyst forecast revision dummy carry significant coefficients of $-0.47(\mathrm{t}$-statistic $=-2.53)$ and $-0.39(\mathrm{t}$-statistic $=-2.38)$. Therefore, the predictability of the IV skew for stock returns is more than three times larger on days with analyst recommendation changes than on other days (-0.70 vs. -0.23$)$ and is more than twice as large as when analysts revise their earnings estimates (-0.62 vs. -0.23$)$. Through a similar calculation as in the previous step, we found that in the IV skew sample, $1.43 \%$ and $3.33 \%$ of the days include analyst recommendation change and analyst forecast revision, approximately $4.23 \%$ and $8.50 \%$ of the return predictability by IV skew are associated with the analyst recommendation change and analyst forecast revision. The interaction term between the IV skew and the analyst initiation dummy is not statistically significant. It can be attributed to the fact that analyst initiations overall tend to be positive news; thus, its impacts on stock returns are better captured by the IV spread, which positively predicts stock returns. Our results are in line with Hayunga and Lung (2013), who also show that the predictive power of options trading on stock returns is stronger when approaching the analyst recommendation change days.

To sum up, we show that options trading activities have significant predictive power over future excess returns. What is more important is that we decompose the predictability regarding different informational analyst-related events. We find that the predictability of options trading on excess returns is significantly related to investors' private information on analyst-related news.

\section{Discussion of the potential information flows between sell-side analysts and options traders}


We show in the previous section that informed options traders have information on analyst-related news. The options trading predictability on the stock return is particularly strong on days prior to analyst-related events. In this section, we will focus on the event of analyst initiation to provide an analysis of the relative merit of three possible explanations regarding how options traders become informed about this analyst-related news.

\subsection{Three hypotheses}

The first hypothesis is analyst tipping: Informed traders acquire information from analysts before public announcements of the recommendation changes, forecast revisions, or initiations. They capitalize on tips by trading in the options market prior to the events such that the excess demand pressure in the options market can predict analyst-related news. The tipping hypothesis is in line with the studies by Irvine, Lipson, and Puckett (2007) and Christophe, Ferri, and Hsieh (2010). The former provide evidence that some institutional investors receive tips from sell-side analysts with regard to forthcoming analysts' reports, and the latter suggests that some traders are tipped by analysts about upcoming downgrades and reveal the tips through short sales.

The second hypothesis is reverse tipping: Informed options traders tip their recent trading activities to the sell-side analysts. In reality, sell-side analysts are usually more junior than buy-side analysts and asset managers, who are arguably better informed. Cen, Dasgupta, and Ragunathan (2012) show that sell-side analysts benefit from buy-side analysts' information production abilities. If some sell-side analysts ask about the views or recent trading activities of informed options traders (e.g., hedge fund managers) to help them write reports, this can also lead to the lead-lag relation between options trading and analyst-related news. 
The third hypothesis, common information, is that informed traders and sell-side analysts analyze the same available materials at hand and draw similar conclusions at the same time. However, informed investors can trade in the options market immediately, while the sell-side analysts need to spend time writing the reports and going through the internal compliance process. Our conversations with analysts suggest that the compliance process may take a few days, which is consistent with the five-day window of our predictability.

Note that the three hypotheses may not be mutually exclusive and can exist at the same time. In following subsections, we will focus on the event of analyst initiation to examine which hypothesis might be the most relevant. As suggested by Irvine, Lipson, and Puckett (2007), analyst initiation is less likely to be correlated with the reverse-tipping argument due to its high costs and low frequency. Therefore, it provides us with clear tests to distinguish the three hypotheses.

\subsection{Analyst tipping vs. reverse tipping}

First, we differentiate the analyst-tipping hypothesis and the reverse-tipping hypothesis through examining the predictability of options trading on analysts' initial recommendations. Irvine, Lipson, and Puckett (2007) argue that it is unlikely that analysts initiate coverage on a stock in response to a tip received from informed traders. First of all, the initiation of coverage is costly and time consuming, and second, the frequency of initiation seems to be too low. During our sample period through 1996 to 2010, one analyst issued 0.77 initiations each year on average. If sell-side analysts responded to tips from asset managers who trade options, the number would be larger. 
Thus, if the reverse-tipping hypothesis dominates, we may not find any predictability of options trading on analysts' initial recommendations. On the contrary, if the analyst-tipping phenomenon prevails, we can still find some predictive power of options trading over analyst initiations. We run pooled regressions in the following form:

$$
\text { initial_rec }_{i, t}=\beta_{0}+\beta_{1} \text { option }_{i, t-5, t-1}+\delta \text { controls }_{i, t-1}+\gamma \text { Year fixed effects }+\varepsilon_{i, t} \text {, }
$$

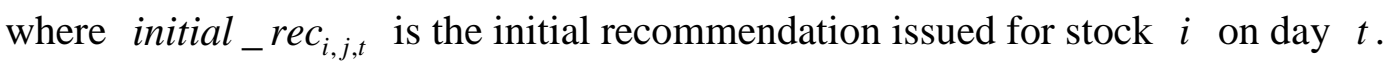

[Table 4 to be inserted here]

Table 4 presents the estimation results. Both the IV spread and the IV skew are significantly correlated with the analyst's initial recommendation. The IV spread positively predicts analysts' initial recommendations with a t-statistic of 4.80, while the IV skew negatively predicts analyst initiations with a t-statistic of -4.03 . The results are more consistent with the analyst-tipping hypothesis.

\subsection{Analyst tipping vs. common information}

The previous results are less consistent with the reverse-tipping line of thought. However, it could be both consistent with the tipping and common-information hypotheses. In this subsection, we distinguish between the analyst-tipping hypothesis and common-information hypothesis following Christophe, Ferri, and Hsieh (2010). We achieve this purpose by studying the relationship between the IV spread/skew and the standardized earnings surprise (SUE) preceding the analyst initiations. The SUE is calculated as is the announced earnings

per share less the corresponding consensus analyst forecast and scaled by the standard 
deviation of the quarterly earnings estimates. We sort our sample into terciles based on the average IV spread and IV skew during the three days prior to the analyst initiations and check the pattern of the SUEs of the most recent calendar quarters.

Under the common-information hypothesis, if both options investors and analysts make predictions about the stock performance using the same fundamental information, such as the earnings performance, we expect to find a more positive (negative) preceding SUE for stocks with higher IV spread (IV skew) before the analyst initiations. On the contrary, we should not anticipate this pattern according to the analyst-tipping hypothesis.

[Table 5 to be inserted here]

As shown in Table 5, the sorting results are inconsistent with the common-information hypothesis. In the case of the IV spread, the mean preceding SUE for the high-minus-low tercile is $-0.006 \%$ (t-statistic $=-0.53$ ). As for the IV skew, the mean preceding SUE of the high-minus-low tercile is $-0.009 \%$ (t-statistic $=-0.80)$. The findings are thus more in line with the analyst-tipping hypothesis.

We admit that the analyses used to differentiate the three hypotheses are not perfect. For instance, the common information shared by options investors and analysts may not be confined to earnings. Nevertheless, our results provide evidence that analyst tipping is most relevant for options traders’ private information on future analyst-related events.

\section{Additional tests}


We perform three additional tests to further support our main hypotheses. First, we examine how the options market liquidity would affect our analyses. Second, we study the post-event trading strategies of options traders. Finally, we conduct an event-based long/short portfolio analysis.

\subsection{Predictability of stock returns and options market liquidity}

Easley, O’Hara, and Srinivas (1998) suggest that the options market would be preferred by informed traders compared to the stock market when the options liquidity is relatively higher. It is thus a natural extension to examine whether our results are stronger when the options market is more liquid. To test this conjecture, we use the options bid-ask spread, which is calculated as the best ask price less the best bid price and scaled by the midpoint as a proxy for the options market illiquidity.

We focus on the event of analyst initiation to be specific about the tipping channel. We add interaction terms of the options bid-ask spread with the informed options trading measure and the initiation dummy variable to equation (4):

$$
\begin{aligned}
\text { exret }_{i, t, t+4}= & \beta_{0}+\left(\beta_{1}+\beta_{2} \text { optbasp }_{i, t-5, t-1}\right) * \text { option }_{i, t-5, t-1}+\left(\beta_{3}+\beta_{4} \text { optbasp }_{i, t-5, t-1}\right) * \text { initiation }_{i, t} * \text { options }_{i, t-5, t-1} \\
& +\beta_{5} \text { initiation }_{i, t}+\text { Scontrols }_{i, t-1}+\gamma \text { Year fixed effects }+\varepsilon_{i, t},
\end{aligned}
$$

where the optbasp $p_{i, t-5, t-1}$ is the average bid-ask spread over the previous week. We expect $\beta_{4}$ to have the opposite sign of $\beta_{3}$, as we anticipate observing less options trading on private information about the analyst-related events when the options market is less liquid, that is, when options have higher bid-ask spreads.

[Table 6 to be inserted here] 
Table 6 reports the regression results for equation (7). The triple interaction between the initiation dummy variable, the options trading measure and the bid-ask spread equals -0.89 for the IV spread (t-statistic $=-1.90)$ and 1.91 for the IV skew (t-statistic $=3.19$ ); both suggest that the predictability of the options trading on future excess returns becomes less related to the private information about analysts' initiations when the options market becomes less liquid.

Overall, consistent with Easley, O’Hara, and Srinivas (1998), we find that less informed investors choose the options market to capitalize on their private information from analysts when the options market liquidity decreases.

\subsection{Options trading measures in the post-event period}

We also examine the trading strategies of options traders after the announcements of analyst-related news. If options traders believe that the market has not fully incorporated the news into stock prices, they would continue to hold their options positions, and the IV spread and IV skew would be expected to remain at their pre-event levels for some time. Alternatively, they would choose to liquidate their options, in which case, one would expect the IV spread and IV skew to revert. In addition, if the events cause a structural change in option risk premiums, one would also expect the IV spread and skew to remain at their pre-event levels. By studying the pattern of the IV spread and skew after the events, we therefore also check for the possibility that the pre-event option prices simply reflect a change in jump or volatility risk premiums. The post-event period options trading is then investigated as follows: 


$$
\text { option }_{i, t+1, t+5}=\beta_{0}+\beta_{1} \text { ret }_{i, t}+\beta_{2} \text { option }_{i, t-5, t-1}+\delta \text { controls }_{i, t-1}+\gamma \text { Year fixed effects }+\varepsilon_{i, t} \text {, }
$$

where the option $_{i, t+1, t+5}$ is the average of the daily informed options trading measures over day $t+1$ to day $t+5$. It can take the value of $\operatorname{spread}_{i, t+1, t+5}$ and $s k e w_{i, t+1, t+5}$. The variable ret $_{i, t}$ is the stock return on the event day.

The coefficient on the event day return $\beta_{1}$ describes the post-event options trading following the event day stock price change. A negative (positive) $\beta_{1}$ for the IV spread (IV skew) suggests that informed traders reduce (or even reverse) their positions after event announcements. In other words, they believe that the market has fully incorporated the analyst-related news. If $\beta_{1}$ is zero, there is no change in the IV spread or skew, consistent with the view that informed traders maintain their options positions, as they believe that the analyst-related news has not been fully incorporated into the stock price (or that option prices have changed structurally due to a change in risk premiums). Finally, a positive (negative) $\beta_{1}$ for the IV spread (IV skew) suggests that informed traders increase their options positions, perhaps because they believe that most of the analyst-related news must still be incorporated into the stock price.

[Table 7 to be inserted here]

Table 7 provides the regression results. For each analyst-related event, we find negative $\beta_{1}$ for the IV spread and positive $\beta_{1}$ for the IV skew, all with statistical significance. The results indicate that options traders quickly reduce their options positions during the week after the release of analyst-related news, and both options trading measures return to their normal levels after the stock price changes. These results also support the assumption that 
there are no structural changes in option risk premiums. In addition, our findings are consistent with existing literature on information-based trading, which shows that informed investors are in aggregate contrarians in the short run. ${ }^{15}$

\subsection{Event-based long/short portfolio analysis}

In addition, we look at the performance of the long/short portfolios formed on the two options trading proxies. Again, we focus on the analyst initiations because they are most informative about the tipping channel. We divide our sample into the initiation group with occurrences of analysts' initiations and the non-event group where none of the three analyst-related events takes place. For each sub-sample, stocks are sorted into deciles every trading day based on the average IV spread or IV skew over the previous week. Abnormal returns with respect to the four Fama-French (1993) and Carhart (1997) factors during post-formation weeks are calculated for the long/short portfolios, with long stocks in the highest decile and short stocks in the lowest decile:

$$
\operatorname{High}_{t}-\operatorname{Low}_{t}=\alpha+\beta_{1}\left(R m_{t}-R f_{t}\right)+\beta_{2} S M B_{t}+\beta_{3} H M L_{t}+\beta_{4} \text { Momentum }_{t}+\varepsilon_{t} \text {, }
$$

[Table 8 to be inserted here]

Table 8 presents abnormal returns for the long/short portfolios in both sub-groups. In the value-weighted case, the IV spread hedge portfolio gains a positive daily abnormal return of 18.70 basis points (t-statistic $=3.39$ ) in the post-formation week on initiation days, and 8.20 basis points (t-statistic $=7.14$ ) on no-event days. The IV skew hedge portfolio earns a negative daily abnormal return of -12.70 basis points (t-statistic $=-2.10)$ for the initiation

${ }^{15}$ See, for example, Brennan and Cao (1996); Lakonishok and Lee (2001); and Watanabe (2008). 
group, and -5.20 basis points $(\mathrm{t}$-statistic $=-4.13)$ for the non-event group. Hence, stocks with high IV spreads (low IV skews) outperform stocks with low IV spreads (high IV skews) and more so around analysts' initiations. ${ }^{16}$

\section{Robustness checks}

For robustness purposes, we address the influence of the inaccuracy of analyst report time stamps and the equity lending fee in this section.

\subsection{Inaccuracy of analyst report time stamps}

Hoechle, Schaub, and Schmid (2013) find that the announcement dates in I/B/E/S are on average delayed by about 0.64 trading days in the period spanning from 1994 to $2001 .^{17}$ Note that we average the IV spread and skew over the 5 trading days before the event. Additionally, we use a 5-day window to calculate stock returns after the event. Hence, we do not expect this delay to be a major issue for our analysis. Nevertheless, to alleviate any concern that the predictability that we documented is driven by the delayed time stamp of I/B/E/S, we conduct a sub-period analysis using data from 2002 to 2010. We find qualitatively similar results for our main hypothesis. The results are not reported for brevity and are available upon request.

\subsection{Lending fees}

A final robustness check concerns the lending fees associated with shorting stocks. If informed investors want to short stocks to capitalize on their private negative information, the

\footnotetext{
${ }^{16}$ We get qualitatively similar results using equal weighting.

17 Bradley, Clarke, Lee, and Ornthanalai (2014) also find that the average time stamp delay for recommendations is around 2.4 hours for NYSE stocks between 2002 and 2007. The majority occur before the market opens. Therefore, this intraday delay would not materially affect our analysis.
} 
excess shorting demand may increase lending fees, which in turn affects the price of puts (through put-call parity) and the IV skew and spread. Therefore, the predictability of IV spread and skew on forthcoming negative analyst-related news is also consistent with the notion that informed traders reveal their private negative information through the lending market instead of the options market.

To address this concern, we conduct our main analysis again and control for lending fees. We use daily lending market data from Data Explorers and find that our main results still hold after controlling for lending fees. The results for this analysis are not reported for brevity and are also available upon request.

\section{Conclusion}

Our paper provides evidence that options trading can predict excess stock returns because informed investors choose the options market to trade on their private information about upcoming analyst-related news, namely the analyst recommendation change, analyst forecast revision, and analyst initiation. Using both the IV spread and the IV skew as informed options trading measures, we decompose the predictability of options trading on stock returns. We find that $10.74 \%$ of the predictive power of the IV spread and $13.20 \%$ of the predictive power of the IV skew come from informed options traders' private information associated with the upcoming analyst-related news. In this way, we find the information sources that lie beneath the documented predictive patterns. Our results are most consistent with the analyst-tipping hypothesis that some options investors receive tips from analysts about their future reports. The results are more pronounced when the options market is more liquid. 


\section{Appendix: Estimating two-way clustered standard errors}

In OLS regressions, residuals are assumed to be independent and identically distributed (i.i.d.) to obtain unbiased standard errors. However, regressions using panel data often suffer from correlated residuals across firms or across time, leading to biased standard errors and t-statistics. Petersen (2009) suggests that the most efficient way to address this concern is to double cluster the standard errors along both time and firm dimensions, which simultaneously adjusts for the cross-sectional and serial correlations in residuals.

Consider the following regression with the input panel data covering $i=1, \cdots, N$ firms and $t=1, \cdots, T$ time periods:

$$
y_{i, t}=\mathbf{x}_{\mathbf{i}, \mathbf{t}}^{\prime} \boldsymbol{\beta}+\varepsilon_{i, t},
$$

where $y_{i, t}$ is the dependent variable, $\mathbf{x}_{i, t}$ is a $N \times 1$ vector, and $\boldsymbol{\beta}$ is the coefficient vector. The error term $\varepsilon_{i, t}$ may exhibit correlations either across firms or across time, violating the i.i.d. assumption.

To ensure unbiased standard errors, the adjusted variance-covariance matrix after the double clustering on both time and firm dimensions is estimated to be:

$$
\text { Adj } V_{\text {time\& firm }}=V_{\text {time }}+V_{\text {firm }}-V_{\text {White }} \text {, }
$$

where $V_{\text {time }}$ is the variance-covariance matrix with standard errors clustered by time to allow for the cross-sectional correlation in residuals, $V_{\text {firm }}$ is the variance-covariance matrix with standard errors clustered by firm to allow for the serial correlation, and $V_{\text {White }}$ is the White variance-covariance matrix. ${ }^{18}$ Petersen (2009) shows that this methodology can substantially reduce the bias in standard errors that is caused by the dependence in residuals.

18 See also Cameron, Gelbach, and Miller (2011); and Thompson (2011). 


\section{References}

Bali, T. G., and Armen Hovakimian, 2009, Volatility spreads and expected stock returns, Management Science 55(11): 1797-1812.

Barber, Brad, Reuven Lehavy, Maureen McNichols, and Brett Trueman, 2001, Can investors profit from the prophets? Security analyst recommendations and stock returns, Journal of Finance 56(2): 531-563.

Bates, D. S., 1991, The crash of '87: Was it expected? The evidence from option markets, Journal of Finance 46(3): 1009-1044.

Black, Fischer, 1975, Fact and fantasy in the use of options, Financial Analysts Journal 31(4): 36-41, 61-72.

Blau, Benjamin M., and Chip Wade, 2012, Informed or speculative: Short selling analyst recommendations, Journal of Banking and Finance 36(1): 14-25.

Boehmer, Ekkehart, C. M. Jones, and Xiaoyan Zhang, 2012, What do short sellers know?, working paper.

Bollen, N. P. B., and R. E. Whaley, 2004, Does net buying pressure affect the shape of implied volatility functions?, Journal of Finance 59(2): 711-753.

Bradley, Daniel, Jonathan Clarke, Suzanne Lee, and Chayawat Ornthanalai, 2014, Are analysts' recommendations informative? Intraday evidence on the impact of time stamp delays, Journal of Finance 69(2): 645-673.

Brennan, M. J., and H. H. Cao, 1996, Information, trade, and derivative securities, Review of Financial Studies 9(1): 163-208.

Cao, Charles, Zhiwu Chen, and J. M. Griffin, 2005, Informational content of option volume prior to takeovers, Journal of Business 78(3): 1073-1109.

Cameron, A. C., J. B. Gelbach, and D. L. Miller, 2011, Robust inference with multiway clustering, Journal of Business and Economic Statistics 29(2): 238-249.

Carhart, M. M., 1997, On persistence in mutual fund performance, Journal of Finance 52(1): 57-82.

Cen, Ling, Sudipto Dasgupta, and Vanitha Ragunathan, 2012, Buy-side participation and information production in earnings conference calls, working paper.

Chakravarty, Sugato, Huseyin Gulen, and Stewart Mayhew, 2004, Informed trading in stock and options markets, Journal of Finance 59(3): 1235-1258.

Chan, Kalok, Y. P. Chung, and Wai-Ming Fong, 2002, The informational role of stock and 
option volume, Review of Financial Studies 15(4): 1049-1075.

Chan, Konan, Li Ge, and T. C. Lin, 2013, Informational content of option trading on acquirer announcement return, Journal of Financial and Quantitative Analysis, forthcoming.

Christophe, S. E., M. G. Ferri, and Jim Hsieh, 2010, Informed trading before analyst downgrades: Evidence from short sellers, Journal of Financial Economics 95(1): 85106.

Cox, J. C., S. A. Ross, and Mark Rubinstein, 1979, Option pricing: A simplified approach, Journal of Financial Economics 7(3): 229-263.

Cremers, Martijn, and David Weinbaum, 2010, Deviations from put-call parity and stock return predictability, Journal of Financial and Quantitative Analysis 45(2): 335-367.

Easley, David, Maureen O'Hara, and P. S. Srinivas, 1998, Option volume and stock prices: Evidence on where informed traders trade, Journal of Finance 53(2): 431-465.

Fama, E. F., and K. R. French, 1993, Common risk factors in the returns on bonds and stocks, Journal of Financial Economics 33 (1): 3-53.

Ge, Li, Mark Humphery-Jenner, and T. C. Lin, 2013, Informed options trading prior to bankruptcy filings, working paper.

Hayunga, D. K., and P. P. Lung, Trading in the options market around the financial analysts' consensus revision, 2013, Journal of Financial and Quantitative Analysis, forthcoming.

Hoechle, Daniel, Nic Schaub, and Markus Schmid, 2013, Time stamp errors and the stock price reaction to analyst recommendation and forecasts revisions, working paper.

Irvine, Paul, Marc Lipson, and Andy Puckett, 2007, Tipping, Review of Financial Studies 20(3): 741-768.

Lung, P. P., and P. T. Xu, 2014, Tipping and option trading, Financial Management, forthcoming.

Jegadeesh, Narasimhan, Joonghyuk Kim, S. D. Krische, and C. M. C. Lee, 2004, Analyzing the analysts: When do recommendations add value?, Journal of Finance 59(3): 10831124.

Jin, Wen, Joshua Livnat, and Yuan Zhang, 2012, Option prices leading equity prices: Superior information discovery or superior information processing?, Journal of Accounting Research 50(2): 401-432s.

Johnson, T. L., and E. C. So, 2012, The option to stock volume ratio and future returns, Journal of Financial Economics 106(2): 262-286. 
Lakonishok, Josef, and Inmoo Lee, 2001, Are insider trades informative?, Review of Financial Studies 14(1): 79-111.

Muravyev, Dmitriy, N. D. Pearson, and J. P. Broussard, 2013, Is there price discovery in equity options?, Journal of Financial Economics 107(2): 259-283.

Newey, W. K., and K. D. West, 1987, A simple, positive semi-definite, heteroskedasticity and autocorrelation consistent covariance matrix, Econometrica 55(3): 703-708.

Ni, S. X., Jun Pan, and A. M. Poteshman, 2008, Volatility information trading in the option market, Journal of Finance 63(3): 1059-1091.

Ofek, Eli, Matthew Richardson, and R. F. Whitelaw, 2004, Limited arbitrage and short sales restrictions: Evidence from the options markets, Journal of Financial Economics 74(2): 305-342.

Pan, Jun, and A. M. Poteshman, 2006, The information in option volume for future stock prices, Review of Financial Studies 19(3): 871-908.

Petersen, Mitchell, 2009, Estimating standard errors in finance panel data sets: Comparing approaches, Review of Financial Studies 22(1): 435-480.

Roll, Richard, Eduardo Schwartz, and Avanidhar Subrahmanyam, 2010, O/S: The relative trading activity in options and stock, Journal of Financial Economics 96(1): 1-17.

Thompson, S. B., 2011, Simple formulas for standard errors that cluster by both firm and time, Journal of Financial Economics 99(1): 1-10.

Watanabe, Masahiro, 2008, Price volatility and investor behavior in an overlapping generations model with information asymmetry, Journal of Finance 63(1): 1540-6261.

Womack, K. L., 1996, Do brokerage analysts' recommendations have investment value?, Journal of Finance 51(1): 137-167.

Xing, Yuhang, Xiaoyang Zhang, and Rui Zhao, 2010, What does the individual option volatility smirk tell us about future equity returns?, Journal of Financial and Quantitative Analysis 45(3): 641-662. 


\section{Table 1: Descriptive statistics}

Table 1 reports descriptive statistics on the analyst-related events and informed options trading proxies. The data on analyst-related events are from the $\mathrm{I} / \mathrm{B} / \mathrm{E} / \mathrm{S}$. The options trading data are provided by the OptionMetrics. The sample period is from January 1996 to December 2010. Recommendation change is the total number of notches changed for a stock. An analyst recommendation equals a number from 5 to 1 , indicating strong buy, buy, hold, underperform, and sell, respectively. Forecast revision is the new analyst consensus less the old one. Initiation is the first recommendation that an analyst gives for a certain stock. When multiple analysts initiate coverage for one stock within one trading day, we take the average of all of the initial recommendations. For each event, we require that all firms included are optioned firms. We exclude analyst-related events that are within five days of quarterly earnings announcements. IV spread is the difference in IVs between matched pairs of call and put options on the same security with identical strike prices and maturities. IV skew is the difference between the IVs of the OTM put option and the ATM call option on the same stock. Firm is the number of firms included. Std is the standard deviation across observations. $\mathrm{N}$ is the number of firm-day observations.

\begin{tabular}{lccccccc}
\hline & Firm & $25 \%$ & Median & $75 \%$ & Mean & Std & N \\
\hline Panel A: Analyst-related events & & & & & & & \\
Analyst recommendation change & 5,591 & -1.188 & -0.155 & 1.004 & -0.131 & 1.526 & 116,302 \\
Analyst forecast revision & 5,486 & -0.007 & -0.001 & 0.002 & -0.005 & 0.099 & 237,808 \\
Analyst initiation & 5,986 & 3.234 & 3.787 & 4.508 & 3.822 & 0.863 & 90,497 \\
Panel B: IV proxies & & & & & & & \\
IV spread & & & & & & & \\
IV skew & 6,629 & -0.034 & -0.009 & 0.014 & -0.011 & 0.064 & $7,083,631$ \\
\hline
\end{tabular}




\section{Table 2: IV spread and excess stock returns}

The table below shows pooled daily regressions of excess returns on the IV spread and its interaction terms with the event dummy variables. Excess return is the stock return in excess of the market return averaged over day $\mathrm{t}$ to day $\mathrm{t}+4$, expressed in percentages. IV spread is averaged over the previous week. Eventday is a dummy variable that equals 1 if the analyst recommendation change, analyst forecast revision, or analyst initiation takes place on day t. Recommend, Forecast, and Initiation are dummy variables indicating the occurrences of each event. Size is the natural logarithm of the market capitalization. $\mathrm{B} / \mathrm{M}$ is the book-to-market ratio. Ret $(w-1)$ is the buy-and-hold stock return over the previous week. Ret $(w-24, w-2)$ is the buy-and-hold stock return over the previous 2 to 24 weeks. Volatility is the daily equity return volatility in the previous month. Turnover is the stock trading volume over the number of shares outstanding. Hskew is the historical daily stock return skewness of the previous month. Stock bid-ask spread is the closing bid-ask spread of the underlying stock, which is the closing ask less the closing bid and divided by the midpoint. Year FE refers to the controlling of the year fixed effects. Estimated standard errors are clustered by firm and calendar quarter. ***, **, and * indicate that the coefficient estimate is significant at the $1 \%, 5 \%$, and $10 \%$ level, respectively.

\begin{tabular}{|c|c|c|c|c|c|c|}
\hline \multirow[b]{2}{*}{ Intercept } & \multicolumn{6}{|c|}{ Dependent variable: Excess return } \\
\hline & $\begin{array}{l}0.015 \\
(1.40)\end{array}$ & $\begin{array}{l}0.034^{*} \\
(1.81)\end{array}$ & $\begin{array}{l}0.015 \\
(1.44)\end{array}$ & $\begin{array}{l}0.035^{*} \\
(1.84)\end{array}$ & $\begin{array}{l}0.016 \\
(1.51)\end{array}$ & $\begin{array}{l}0.035^{*} \\
(1.86)\end{array}$ \\
\hline IV spread & $\begin{array}{c}0.486 * * * \\
(10.43)\end{array}$ & $\begin{array}{c}0.443 * * * \\
(10.04)\end{array}$ & $\begin{array}{c}0.468 * * * \\
(10.33)\end{array}$ & $\begin{array}{c}0.424 * * * \\
(9.56)\end{array}$ & $\begin{array}{c}0.467 * * * \\
(10.36)\end{array}$ & $\begin{array}{c}0.421 * * * \\
(9.54)\end{array}$ \\
\hline Eventday*IV spread & & & $\begin{array}{c}0.620 * * * \\
(3.50)\end{array}$ & $\begin{array}{c}0.661 * * * \\
(3.63)\end{array}$ & & \\
\hline Recommend*IV spread & & & & & $\begin{array}{c}0.985 * * * \\
(3.59)\end{array}$ & $\begin{array}{c}1.158^{* * * *} \\
(4.16)\end{array}$ \\
\hline Forecast*IV spread & & & & & $\begin{array}{c}0.504 * * \\
(2.27)\end{array}$ & $\begin{array}{c}0.527^{* *} \\
(2.48)\end{array}$ \\
\hline Initiation* IV spread & & & & & $\begin{array}{l}0.409 * \\
(1.81)\end{array}$ & $\begin{array}{c}0.458^{* *} \\
(2.00)\end{array}$ \\
\hline Eventday & & & $\begin{array}{l}-0.013 \\
(-1.15)\end{array}$ & $\begin{array}{l}-0.017 \\
(-1.39)\end{array}$ & & \\
\hline Recommend & & & & & $\begin{array}{c}-0.053^{* * *} \\
(-3.30)\end{array}$ & $\begin{array}{c}-0.052^{* * *} \\
(-3.09)\end{array}$ \\
\hline Forecast & & & & & $\begin{array}{c}-0.037 * * * \\
(-2.79)\end{array}$ & $\begin{array}{c}-0.042^{* * *} \\
(-3.08)\end{array}$ \\
\hline Initiation & & & & & $\begin{array}{c}0.044 * * * \\
(4.60)\end{array}$ & $\begin{array}{c}0.039 * * * \\
(4.33)\end{array}$ \\
\hline Size & & $\begin{array}{c}-0.0002 \\
(-0.06)\end{array}$ & & $\begin{array}{l}0.0001 \\
(0.03)\end{array}$ & & $\begin{array}{l}0.0005 \\
(0.13)\end{array}$ \\
\hline $\mathrm{B} / \mathrm{M}$ & & $\begin{array}{c}0.0003^{* *} \\
(2.32)\end{array}$ & & $\begin{array}{c}0.0003 * * \\
(2.29)\end{array}$ & & $\begin{array}{c}0.0003^{* *} \\
(2.26)\end{array}$ \\
\hline Ret $(w-1)$ & & $\begin{array}{c}-0.371^{* * *} \\
(-3.51)\end{array}$ & & $\begin{array}{c}-0.371^{* * *} \\
(-3.50)\end{array}$ & & $\begin{array}{c}-0.372 * * * \\
(-3.51)\end{array}$ \\
\hline Ret $(w-24, w-2)$ & & $\begin{array}{l}0.008 \\
(0.41)\end{array}$ & & $\begin{array}{l}0.008 \\
(0.40)\end{array}$ & & $\begin{array}{l}0.008 \\
(0.39)\end{array}$ \\
\hline Volatility & & $\begin{array}{l}0.201 \\
(0.26)\end{array}$ & & $\begin{array}{l}0.211 \\
(0.27)\end{array}$ & & $\begin{array}{l}0.220 \\
(0.28)\end{array}$ \\
\hline Turnover & & $\begin{array}{l}-0.071 \\
(-0.57)\end{array}$ & & $\begin{array}{l}-0.063 \\
(-0.52)\end{array}$ & & $\begin{array}{l}-0.054 \\
(-0.44)\end{array}$ \\
\hline Hskew & & $\begin{array}{c}0.015^{* * *} \\
(4.99)\end{array}$ & & $\begin{array}{c}0.015^{* * * *} \\
(4.98)\end{array}$ & & $\begin{array}{c}0.015^{* * *} \\
(4.97)\end{array}$ \\
\hline Stock bid-ask spread & & $\begin{array}{l}-0.006 \\
(-0.55)\end{array}$ & & $\begin{array}{l}-0.006 \\
(-0.55)\end{array}$ & & $\begin{array}{l}-0.006 \\
(-0.53)\end{array}$ \\
\hline Year FE & No & Yes & No & Yes & No & Yes \\
\hline $\mathrm{N}$ & $7,382,894$ & $6,284,049$ & $7,382,894$ & $6,284,049$ & $7,382,894$ & $6,284,049$ \\
\hline Adj R2 (\%) & 0.03 & 0.15 & 0.04 & 0.16 & 0.04 & 0.16 \\
\hline
\end{tabular}


Table 3: IV skew and excess stock returns

This table provides pooled daily regressions of excess stock returns on the IV skew and its interactions with the event dummy variables. Excess return is the stock return in excess of the market return averaged over day $t$ to day $t+4$, expressed in percentages. IV skew is the average IV skew over the previous week. Eventday is a dummy variable that equals 1 if the analyst recommendation change, the analyst forecast revision, or the analyst initiation takes place on day t. Recommend, Forecast, and Initiation are dummy variables indicating the occurrences for each event. Size is the natural logarithm of the firm's market capitalization. B/M is the book-to-market ratio. Ret ( $w-1)$ is the buy-and-hold stock return over the previous week. Ret $(w-24, w-2)$ is the buy-and-hold stock return over the previous 2 to 24 weeks. Volatility is the daily equity return volatility in the previous month. Turnover is the stock trading volume over the number of shares outstanding. Hskew is the historical daily stock return skewness of the previous month. Stock bid-ask spread is the closing bid-ask spread of the underlying stock, which is the closing ask less the closing bid and divided by the midpoint. Year FE refers to the controlling of the year fixed effects. Estimated standard errors are clustered by firm and calendar quarter. $* * *, * *$, and $*$ indicate that the coefficient estimate is significant at the $1 \%, 5 \%$, and $10 \%$ level, respectively.

\begin{tabular}{|c|c|c|c|c|c|c|}
\hline \multirow[b]{2}{*}{ Intercept } & \multicolumn{6}{|c|}{ Dependent variable: Excess return } \\
\hline & $\begin{array}{c}0.020^{* *} \\
(1.96)\end{array}$ & $\begin{array}{c}0.056 * * * \\
(2.97)\end{array}$ & $\begin{array}{r}0.019 * \\
(1.90)\end{array}$ & $\begin{array}{c}0.056 * * * \\
(2.95)\end{array}$ & $\begin{array}{c}0.020^{* *} \\
(1.96)\end{array}$ & $\begin{array}{c}0.056^{* * *} \\
(2.96)\end{array}$ \\
\hline IV skew & $\begin{array}{c}-0.239 * * * \\
(-4.44)\end{array}$ & $\begin{array}{c}-0.242 * * * \\
(-5.15)\end{array}$ & $\begin{array}{c}-0.225^{* * *} \\
(-4.19)\end{array}$ & $\begin{array}{c}-0.227 * * * \\
(-4.79)\end{array}$ & $\begin{array}{c}-0.224 * * * \\
(-4.19)\end{array}$ & $\begin{array}{c}-0.226 * * * \\
(-4.77)\end{array}$ \\
\hline Eventday*IV skew & & & $\begin{array}{c}-0.425 * * * \\
(-3.20)\end{array}$ & $\begin{array}{c}-0.396 * * * \\
(-2.88)\end{array}$ & & \\
\hline Recommend*IV skew & & & & & $\begin{array}{c}-0.447^{* *} \\
(-2.54)\end{array}$ & $\begin{array}{c}-0.469 * * \\
(-2.53)\end{array}$ \\
\hline Forecast*IV skew & & & & & $\begin{array}{c}-0.406^{* *} \\
(-2.43)\end{array}$ & $\begin{array}{c}-0.389 * * \\
(-2.38)\end{array}$ \\
\hline Initiation*IV skew & & & & & $\begin{array}{c}-0.346^{*} \\
(-1.79)\end{array}$ & $\begin{array}{l}-0.279 \\
(-1.33)\end{array}$ \\
\hline Eventday & & & $\begin{array}{l}0.012 \\
(1.05)\end{array}$ & $\begin{array}{l}0.008 \\
(0.76)\end{array}$ & & \\
\hline Recommend & & & & & $\begin{array}{c}-0.043^{* *} \\
(-2.57)\end{array}$ & $\begin{array}{c}-0.040^{* *} \\
(-2.35)\end{array}$ \\
\hline Forecast & & & & & $\begin{array}{l}0.002 \\
(0.16)\end{array}$ & $\begin{array}{l}-0.002 \\
(-0.18)\end{array}$ \\
\hline Initiation & & & & & $\begin{array}{c}0.058^{* * *} \\
(3.74)\end{array}$ & $\begin{array}{c}0.053 * * * \\
(3.21)\end{array}$ \\
\hline Size & & $\begin{array}{l}-0.002 \\
(-0.50)\end{array}$ & & $\begin{array}{l}-0.002 \\
(-0.44)\end{array}$ & & $\begin{array}{l}-0.001 \\
(-0.37)\end{array}$ \\
\hline $\mathrm{B} / \mathrm{M}$ & & $\begin{array}{c}0.0001 \\
(0.81)\end{array}$ & & $\begin{array}{l}0.0001 \\
(0.79)\end{array}$ & & $\begin{array}{l}0.0001 \\
(0.77)\end{array}$ \\
\hline Ret $(w-1)$ & & $\begin{array}{c}-0.461^{* * * *} \\
(-4.47)\end{array}$ & & $\begin{array}{c}-0.461^{* * *} \\
(-4.46)\end{array}$ & & $\begin{array}{c}-0.462 * * * \\
(-4.46)\end{array}$ \\
\hline Ret $(w-24, w-2)$ & & $\begin{array}{l}0.006 \\
(0.24)\end{array}$ & & $\begin{array}{l}0.005 \\
(0.23)\end{array}$ & & $\begin{array}{l}0.005 \\
(0.23)\end{array}$ \\
\hline Volatility & & $\begin{array}{l}-0.395 \\
(-0.50)\end{array}$ & & $\begin{array}{l}-0.384 \\
(-0.48)\end{array}$ & & $\begin{array}{l}-0.376 \\
(-0.47)\end{array}$ \\
\hline Turnover & & $\begin{array}{l}-0.160 \\
(-1.31)\end{array}$ & & $\begin{array}{l}-0.156 \\
(-1.29)\end{array}$ & & $\begin{array}{l}-0.149 \\
(-1.24)\end{array}$ \\
\hline Hskew & & $\begin{array}{c}0.019 * * * \\
(5.53)\end{array}$ & & $\begin{array}{c}0.019 * * * \\
(5.52)\end{array}$ & & $\begin{array}{c}0.019 * * * \\
(5.51)\end{array}$ \\
\hline Stock bid-ask spread & & $\begin{array}{l}-0.009 \\
(-0.64)\end{array}$ & & $\begin{array}{l}-0.009 \\
(-0.64)\end{array}$ & & $\begin{array}{l}-0.009 \\
(-0.63)\end{array}$ \\
\hline Year FE & No & Yes & No & Yes & No & Yes \\
\hline $\mathrm{N}$ & $4,627,618$ & $3,939,823$ & $4,627,618$ & $3,939,823$ & $4,627,618$ & $3,939,823$ \\
\hline Adj R2 (\%) & 0.02 & 0.16 & 0.02 & 0.17 & 0.02 & 0.17 \\
\hline
\end{tabular}




\section{Table 4: IV spread/skew and analyst initiations}

This table shows the results of pooled OLS regressions of analysts' initial recommendations on the IV spread/skew. Initial recommendation is the first recommendation issued by an analyst for a stock. An analyst recommendation equals a number from 5 to 1, indicating strong buy, buy, hold, underperform, and sell, respectively. When multiple analysts initiate coverage for one stock within one trading day, we take the average of all of the initial recommendations. Option refers to the IV spread and the IV skew. IV spread is the average IV spread over the previous week. IV skew is the average IV skew over the previous week. Size is the natural logarithm of the firm's market capitalization. $\mathrm{B} / \mathrm{M}$ is the book-to-market ratio. Ret $(w-1)$ is the buy-and-hold stock return over the previous week. Ret $(w-24, w-2)$ is the buy-and-hold stock return over the previous 2 to 24 weeks. Volatility is the daily equity return volatility for the previous month. Turnover is the stock trading volume over the number of shares outstanding. Hskew is the historical daily stock return skewness of the previous month. Stock bid-ask spread is the closing bid-ask spread of the underlying stock, which is the closing ask less the closing bid and divided by the midpoint. Year FE refers to the controlling of the year fixed effects. Estimated standard errors are clustered by firm and calendar quarter. ***, **, and * indicate that the coefficient estimate is significant at the $1 \%, 5 \%$, and $10 \%$ level, respectively.

\begin{tabular}{|c|c|c|c|c|}
\hline \multirow{4}{*}{ Intercept } & \multicolumn{4}{|c|}{ Dependent variable: Initial recommendation } \\
\hline & \multicolumn{2}{|c|}{ IV spread } & \multicolumn{2}{|c|}{ IV skew } \\
\hline & $3.781 * * *$ & $3.782^{* * *}$ & $3.837 * * *$ & $3.780 * * *$ \\
\hline & $(137.50)$ & $(93.11)$ & $(118.16)$ & $(86.25)$ \\
\hline \multirow[t]{2}{*}{ Option } & $0.315^{*}$ & $0.674^{* * *}$ & $-0.739 * * *$ & $-0.428 * * *$ \\
\hline & $(1.64)$ & $(4.80)$ & $(-4.70)$ & $(-4.03)$ \\
\hline \multirow[t]{2}{*}{ Size } & & $-0.037 * * *$ & & $-0.033 * * *$ \\
\hline & & $(-7.05)$ & & $(-5.41)$ \\
\hline \multirow[t]{2}{*}{$\mathrm{B} / \mathrm{M}$} & & -0.002 & & -0.002 \\
\hline & & $(-1.46)$ & & $(-1.63)$ \\
\hline \multirow[t]{2}{*}{ Ret $(w-1)$} & & $0.320 * * *$ & & $0.289 * * *$ \\
\hline & & $(4.06)$ & & $(3.51)$ \\
\hline \multirow[t]{2}{*}{ Ret $(w-24, w-2)$} & & $0.121 * * *$ & & $0.089 * * *$ \\
\hline & & $(5.83)$ & & $(5.09)$ \\
\hline \multirow[t]{2}{*}{ Volatility } & & -0.358 & & -0.238 \\
\hline & & $(-0.62)$ & & $(-0.41)$ \\
\hline \multirow[t]{2}{*}{ Turnover } & & $-0.493 *$ & & $-0.532 * *$ \\
\hline & & $(-1.77)$ & & $(-2.28)$ \\
\hline \multirow[t]{2}{*}{ Hskew } & & 0.003 & & -0.003 \\
\hline & & $(0.58)$ & & $(-0.44)$ \\
\hline \multirow[t]{2}{*}{ Stock bid-ask spread } & & $-0.023^{* *}$ & & -0.002 \\
\hline & & $(-2.13)$ & & $(-0.13)$ \\
\hline Year FE & No & Yes & No & Yes \\
\hline $\mathrm{N}$ & 50,547 & 43,872 & 35,199 & 30,885 \\
\hline Adj R2 (\%) & 0.02 & 5.33 & 0.25 & 5.84 \\
\hline
\end{tabular}




\section{Table 5: IV spread/skew and earnings performance}

This table displays the mean of earnings performance for sub-samples categorized by the IV spread and the IV skew. For each analyst's initial recommendation, stocks are sorted into terciles based on the average IV spread or IV skew over three days prior to the events. High refers to the top tercile with the highest IV spread/skew, and Low is the bottom tercile with the lowest IV spread/skew. SUE is the standardized unexpected earnings, which is calculated as the announced quarterly EPS less the corresponding consensus analyst forecast and scaled by the standard deviation of the quarterly earnings estimates. Preceding SUE is the mean of the SUEs in the quarter that precedes the analyst initiation. $\mathrm{N}$ is the number of events for each tercile. The column High-Low reports the difference in the mean of Preceding SUEs between high and low IV spread/skew sub-samples.

\begin{tabular}{llcccc}
\hline & \multicolumn{5}{c}{ IV proxy quintiles } \\
\hline \multirow{2}{*}{ Panel A: IV spread } & & High & Median & Low & High-Low \\
& & & & & \\
& Preceding SUE & $0.039 \%$ & $0.059 \%$ & $0.045 \%$ & $-0.006 \%$ \\
Analyst initiation & t-stat & $(5.15)$ & $(9.30)$ & $(4.78)$ & $(-0.53)$ \\
& $\mathrm{N}$ & 10,503 & 10,504 & 10,503 & \\
\multirow{2}{*}{ Panel B: IV skew } & & & & & \\
& & & & & \\
Analyst initiation & Preceding SUE & $0.054 \%$ & $0.072 \%$ & $0.063 \%$ & $-0.009 \%$ \\
& t-stat & $(5.71)$ & $(10.50)$ & $(10.53)$ & $(-0.80)$ \\
& $\mathrm{N}$ & 7,163 & 7,164 & 7,164 & \\
\hline
\end{tabular}




\section{Table 6: Options market liquidity and stock return predictability}

This table shows the effects of option bid-ask spread as a proxy for the options market illiquidity. Excess return is the stock return in excess of the market return averaged over day t to day $t+4$, expressed in percentages. Option refers to the IV spread and the IV skew. IV spread is the average IV spread over the previous week. IV skew is the average IV skew over the previous week. Initiation is a dummy variable that equals 1 if the analyst initiation takes place on day t. Optbasp is the option bid-ask spread, calculated as the best offer price less the best bid price scaled by the midpoint, averaged over the previous week. Size is the natural logarithm of the firm's market capitalization. $\mathrm{B} / \mathrm{M}$ is the book-to-market ratio. Ret $(w-1)$ is the buy-and-hold stock return over the previous week. Ret $(w-24, w-2)$ is the buy-and-hold stock return over the previous 2 to 24 weeks. Volatility is the daily equity return volatility for the previous month. Turnover is the stock trading volume over the number of shares outstanding. Hskew is the historical daily stock return skewness of the previous month. Stock bid-ask spread is the closing bid-ask spread of the underlying stock, which is the closing ask less the closing bid and divided by the midpoint. Year FE refers to the controlling of the year fixed effects. Standard errors are clustered by firm and calendar quarter. ***, **, and * indicate that the coefficient estimate is significant at the $1 \%, 5 \%$, and $10 \%$ level, respectively.

\begin{tabular}{|c|c|c|c|c|}
\hline \multirow[b]{3}{*}{ Intercept } & \multicolumn{4}{|c|}{ Dependent variable: Excess return } \\
\hline & \multicolumn{2}{|c|}{ IV spread } & \multicolumn{2}{|c|}{ IV skew } \\
\hline & $\begin{array}{l}0.016 \\
(1.47)\end{array}$ & $\begin{array}{c}0.034^{*} \\
(1.78)\end{array}$ & $\begin{array}{c}0.024^{* *} \\
(2.42)\end{array}$ & $\begin{array}{c}0.055^{* * *} \\
(2.95)\end{array}$ \\
\hline Option & $\begin{array}{c}0.718 * * * \\
(8.98)\end{array}$ & $\begin{array}{c}0.657 * * * \\
(8.72)\end{array}$ & $\begin{array}{c}-0.429 * * * \\
(-4.37)\end{array}$ & $\begin{array}{c}-0.414 * * * \\
(-4.99)\end{array}$ \\
\hline Option*Optbasp & $\begin{array}{c}-0.447 * * * \\
(-5.77)\end{array}$ & $\begin{array}{c}-0.417 * * * \\
(-5.43)\end{array}$ & $\begin{array}{c}0.242^{* * *} \\
(3.11)\end{array}$ & $\begin{array}{c}0.225^{* * * *} \\
(3.38)\end{array}$ \\
\hline Initiation*Option & $\begin{array}{c}0.856^{* *} \\
(2.20)\end{array}$ & $\begin{array}{c}0.897^{* *} \\
(2.16)\end{array}$ & $\begin{array}{c}-1.153 * * * \\
(-3.40)\end{array}$ & $\begin{array}{c}-1.050 * * * \\
(-2.87)\end{array}$ \\
\hline Initiation*Option*Optbasp & $\begin{array}{c}-0.960 * * \\
(-2.25)\end{array}$ & $\begin{array}{c}-0.886 * \\
(-1.90)\end{array}$ & $\begin{array}{c}1.299 * * * \\
(3.75)\end{array}$ & $\begin{array}{c}1.191^{* * * *} \\
(3.19)\end{array}$ \\
\hline Initiation & $\begin{array}{c}0.040^{* * *} \\
(3.95)\end{array}$ & $\begin{array}{c}0.036^{* * *} \\
(3.64)\end{array}$ & $\begin{array}{c}0.073^{* * *} \\
(4.74)\end{array}$ & $\begin{array}{c}0.067^{* * *} \\
(4.03)\end{array}$ \\
\hline Size & & $\begin{array}{l}-0.0001 \\
(-0.03)\end{array}$ & & $\begin{array}{l}-0.001 \\
(-0.25)\end{array}$ \\
\hline $\mathrm{B} / \mathrm{M}$ & & $\begin{array}{c}0.0003^{* *} \\
(2.29)\end{array}$ & & $\begin{array}{c}0.0001 \\
(0.76)\end{array}$ \\
\hline Ret $(w-1)$ & & $-0.366 * * *$ & & $-0.459 * * *$ \\
\hline Ret $(w-24, w-2)$ & & $\begin{array}{c}(-3.47) \\
0.009 \\
(0.43)\end{array}$ & & $\begin{array}{c}(-4.46) \\
0.005 \\
(0.21)\end{array}$ \\
\hline Volatility & & 0.221 & & -0.312 \\
\hline Turnover & & $\begin{array}{c}(0.29) \\
-0.060 \\
(-0.49)\end{array}$ & & $\begin{array}{l}(-0.39) \\
-0.136 \\
(-1.12)\end{array}$ \\
\hline Hskew & & $0.015^{* * *}$ & & $0.019 * * *$ \\
\hline Stock bid-ask spread & & $\begin{array}{c}(4.96) \\
-0.006 \\
(-0.55)\end{array}$ & & $\begin{array}{l}(5.47) \\
-0.009 \\
(-0.63)\end{array}$ \\
\hline Year FE & No & Yes & No & Yes \\
\hline $\mathrm{N}$ & $7,380,914$ & $6,282,721$ & $4,626,611$ & 3,939,198 \\
\hline Adj R2 (\%) & 0.04 & 0.16 & 0.03 & 0.17 \\
\hline
\end{tabular}




\section{Table 7: IV spread/skew in post-event period}

The table below provides pooled OLS regressions of the post-event options trading proxies on the event day stock returns. Regressions are conducted for sub-samples of three types of events separately. Post-proxy takes the value of post-spread/post-skew, which is the average IV spread/skew over the post-event week, expressed in percentages. Pre-proxy takes the value of the average IV spread/skew over the pre-event week, expressed in percentages. Ret $(t=0)$ is the stock return on the event day. Size is the natural logarithm of the firm's market capitalization. B/M is the book-to-market ratio. Ret $(w-1)$ is the buy-and-hold stock return over the previous week. Ret $(w-24, w-2)$ is the buy-and-hold stock return over the previous 2 to 24 weeks. Volatility is the daily equity return volatility for the previous month. Turnover is the stock trading volume over the number of shares outstanding. Hskew is the historical daily stock return skewness of the previous month. Stock bid-ask spread is the closing bid-ask spread of the underlying stock, which is the closing ask less the closing bid and divided by the midpoint. Year FE refers to the controlling of the year fixed effects. Standard errors are clustered by firm and calendar quarter. $* * *, * *$, and * indicate that the coefficient is significant at the $1 \%, 5 \%$, and $10 \%$ level, respectively.

\begin{tabular}{|c|c|c|c|c|c|c|}
\hline & \multicolumn{6}{|c|}{ Dependent variable: Post-proxy } \\
\hline & \multicolumn{2}{|c|}{ Recommendation change } & \multicolumn{2}{|c|}{ Forecast revision } & \multicolumn{2}{|c|}{ Analyst initiation } \\
\hline & IV spread & IV skew & IV spread & $\underline{\text { IV skew }}$ & $\underline{\text { IV spread }}$ & $\underline{\text { IV skew }}$ \\
\hline Intercept & $\begin{array}{c}-1.601^{* * *} \\
(-4.29)\end{array}$ & $\begin{array}{c}8.229 * * * \\
(12.15)\end{array}$ & $\begin{array}{c}-1.378^{* * *} \\
(-3.80)\end{array}$ & $\begin{array}{c}9.133^{* * *} \\
(13.90)\end{array}$ & $\begin{array}{c}-0.176^{* *} \\
(-2.07)\end{array}$ & $\begin{array}{c}2.852 * * * \\
(14.60)\end{array}$ \\
\hline $\operatorname{Ret}(t=0)$ & $\begin{array}{c}-3.612 * * * \\
(-5.47)\end{array}$ & $\begin{array}{c}1.829 * * * \\
(2.67)\end{array}$ & $\begin{array}{c}-2.892^{* * *} \\
(-3.59)\end{array}$ & $\begin{array}{c}0.980 * \\
(1.66)\end{array}$ & $\begin{array}{c}-5.356^{* * *} \\
(-7.61)\end{array}$ & $\begin{array}{c}2.070 * * \\
(1.98)\end{array}$ \\
\hline Pre-proxy & $\begin{array}{c}0.475^{* * *} \\
(19.71)\end{array}$ & $\begin{array}{c}0.526 * * * \\
(26.14)\end{array}$ & $\begin{array}{c}0.485^{* * *} \\
(27.32)\end{array}$ & $\begin{array}{c}0.516^{* * *} \\
(22.21)\end{array}$ & $\begin{array}{c}0.464^{* * *} \\
(14.23)\end{array}$ & $\begin{array}{c}0.523^{* * *} \\
(23.87)\end{array}$ \\
\hline Size & $\begin{array}{c}0.066^{* * *} \\
(3.99)\end{array}$ & $\begin{array}{c}-0.272 * * * \\
(-9.88)\end{array}$ & $\begin{array}{c}0.060 * * * \\
(3.77)\end{array}$ & $\begin{array}{c}-0.314^{* * *} \\
(-11.54)\end{array}$ & $\begin{array}{c}0.053^{* * *} \\
(3.12)\end{array}$ & $\begin{array}{c}-0.282^{* * *} \\
(-8.84)\end{array}$ \\
\hline $\mathrm{B} / \mathrm{M}$ & $\begin{array}{l}0.002 \\
(0.56)\end{array}$ & $\begin{array}{l}-0.008 \\
(-1.10)\end{array}$ & $\begin{array}{l}-0.010 \\
(-0.80)\end{array}$ & $\begin{array}{l}0.031 \\
(1.14)\end{array}$ & $\begin{array}{c}0.005^{* *} \\
(2.33)\end{array}$ & $\begin{array}{l}0.009 \\
(0.54)\end{array}$ \\
\hline $\operatorname{Ret}(w-1)$ & $\begin{array}{l}-0.046 \\
(-0.06)\end{array}$ & $\begin{array}{l}-1.535 \\
(-1.60)\end{array}$ & $\begin{array}{l}1.228 \\
(1.05)\end{array}$ & $\begin{array}{c}-3.367^{* * *} \\
(-4.19)\end{array}$ & $\begin{array}{l}0.872 \\
(0.82)\end{array}$ & $\begin{array}{l}-0.714 \\
(-1.03)\end{array}$ \\
\hline Ret $(w-24, w-2)$ & $\begin{array}{l}-0.121^{*} \\
(-1.93)\end{array}$ & $\begin{array}{c}-0.405^{* * *} \\
(-4.29)\end{array}$ & $\begin{array}{l}-0.083^{*} \\
(-1.81)\end{array}$ & $\begin{array}{c}-0.494 * * * \\
(-4.92)\end{array}$ & $\begin{array}{l}-0.087 \\
(-1.52)\end{array}$ & $\begin{array}{c}-0.438 * * * \\
(-4.32)\end{array}$ \\
\hline Volatility & $\begin{array}{c}-8.730 * * \\
(-2.51)\end{array}$ & $\begin{array}{c}15.584^{* * *} \\
(3.16)\end{array}$ & $\begin{array}{c}-11.837 * * * \\
(-2.94)\end{array}$ & $\begin{array}{c}19.777^{* * *} \\
(4.13)\end{array}$ & $\begin{array}{c}-11.413^{* * *} \\
(-3.37)\end{array}$ & $\begin{array}{c}9.361^{* *} \\
(2.43)\end{array}$ \\
\hline Turnover & $\begin{array}{l}1.059 \\
(0.64)\end{array}$ & $\begin{array}{l}-1.467 \\
(-0.53)\end{array}$ & $\begin{array}{l}1.516 \\
(0.63)\end{array}$ & $\begin{array}{c}-8.877^{* * *} \\
(-3.19)\end{array}$ & $\begin{array}{l}0.734 \\
(0.57)\end{array}$ & $\begin{array}{c}-4.838 * * * \\
(-3.76)\end{array}$ \\
\hline Hskew & $\begin{array}{c}-0.087^{* *} \\
(-2.46)\end{array}$ & $\begin{array}{c}0.122 * * * \\
(3.17)\end{array}$ & $\begin{array}{c}-0.125^{* * *} \\
(-3.06)\end{array}$ & $\begin{array}{l}0.047 \\
(1.44)\end{array}$ & $\begin{array}{l}-0.052 * \\
(-1.91)\end{array}$ & $\begin{array}{l}-0.022 \\
(-0.56)\end{array}$ \\
\hline Stock bid-ask spread & $\begin{array}{l}-0.034 \\
(-0.98)\end{array}$ & $\begin{array}{c}0.184^{* *} \\
(2.49)\end{array}$ & $\begin{array}{l}0.015 \\
(0.38)\end{array}$ & $\begin{array}{c}0.125^{*} \\
(1.74)\end{array}$ & $\begin{array}{l}-0.034 \\
(-0.71)\end{array}$ & $\begin{array}{c}0.137^{*} \\
(1.87)\end{array}$ \\
\hline Year FE & Yes & Yes & Yes & Yes & Yes & Yes \\
\hline $\mathrm{N}$ & 70,487 & 46,583 & 156,018 & 108,690 & 42,672 & 27,830 \\
\hline Adj R2 (\%) & 22.40 & 30.13 & 24.23 & 31.97 & 23.06 & 30.15 \\
\hline
\end{tabular}




\section{Table 8: Four-factor analysis on long/short portfolios}

This table displays the four-factor abnormal returns for long/short portfolios formed by sorting on the IV spread and IV skew. We divide the whole sample into an initiation group and a non-event group based on occurrences of analyst initiations. For each sub-sample, stocks are sorted into decile portfolios every trading day based on the average IV spread or IV skew over the previous week. Abnormal returns during the post-formation week with regard to the four Fama-French (1993) and Carhart (1997) factors are calculated for the value-weighted long/short portfolios, which long stocks in the top decile and short in the bottom decile. Alpha is the four-factor abnormal return obtained, expressed in percentages. Rm - Rf, SMB, HML, and Momentum are the four factors of the market excess return, the small-minus-big, the high-minus-low, and the momentum. The Newey-West (1987) t-statistics are computed to adjust for the autocorrelations. ***, **, and * indicate that the coefficient estimate is significant at the $1 \%, 5 \%$, and $10 \%$ level, respectively.

\begin{tabular}{lcccc}
\hline & \multicolumn{4}{c}{ Dependent variable: High - low } \\
\cline { 2 - 5 } & \multicolumn{3}{c}{ IV spread } & IV skew \\
\cline { 2 - 5 } Alpha & $0.187^{* * *}$ & $\underline{\text { No-event }}$ & $\underline{\text { Initiation }}$ & No-event \\
& $(3.39)$ & $0.082^{* * *}$ & $-0.127^{* * *}$ & $-0.052^{* * *}$ \\
Rm - Rf & 0.056 & $(7.14)$ & $(-2.10)$ & $(-4.13)$ \\
& $(1.47)$ & -0.011 & 0.051 & -0.007 \\
SMB & $-0.179^{*}$ & $(-1.52)$ & $(0.99)$ & $(-0.91)$ \\
& $(-1.76)$ & -0.013 & 0.094 & 0.022 \\
HML & -0.001 & $(-0.82)$ & $(0.97)$ & $(1.39)$ \\
& $(-0.01)$ & $-0.027^{* *}$ & 0.151 & $0.080^{* * *}$ \\
Momentum & -0.044 & $(-2.12)$ & $(1.29)$ & $(4.52)$ \\
& $(-0.76)$ & $-0.038^{* * *}$ & 0.049 & $-0.075^{* * *}$ \\
\hline N & 1,777 & $(-3.12)$ & $(0.71)$ & $(-5.94)$ \\
Adj R2 (\%) & 0.27 & 3,774 & 1,342 & 3,774 \\
\hline
\end{tabular}

